\title{
A hospital-wide screening programme to control an outbreak of vancomycin-resistant enterococci in a large tertiary hospital in Hong Kong
}

\author{
Christopher KC Lai *, Stephenie YN Wong, Shirley SY Lee, HK Siu, CY Chiu, Dominic NC Tsang, \\ Margaret PY Ip, CT Hung
}

\section{A B S T R A C T}

Introduction: Apart from individual small-scale outbreaks, infections with vancomycin-resistant enterococci are uncommon in Hong Kong. A major outbreak of vancomycin-resistant enterococci, however, occurred at a large tertiary hospital in 2013. We describe the successful control of this outbreak and share the lessons learned.

Methods: In 2013, there was an abnormal increase in the incidence of vancomycin-resistant enterococci carriage compared with baseline in multiple clinical departments at Queen Elizabeth Hospital. A multipronged approach was adopted that included a 10-week hospital-wide active screening programme, which aimed to identify and isolate hidden vancomycin-resistant enterococci carriers among all in-patients. The identified carriers were completely segregated in designated wards where applicable. Other critical infection control measures included directly observed hand hygiene and environmental hygiene. A transparent and open disclosure approach was adopted throughout the outbreak.

Results: The infection control measures were successfully implemented. The active screening of vancomycin-resistant enterococci was conducted between 30 September and 10 November 2013. A total of 7053 rectal swabs were collected from patients in 46 hospital wards from 11 departments.

This article was published on $24 \mathrm{Feb}$ 2017 at www.hkmj.org. The overall carriage rate of vancomycin-resistant enterococci was $2.8 \%$ (201/7053). Pulsed-field gel

clone. We curbed the outbreak and kept the colonisation of vancomycin-resistant enterococci among patients at a pre-upsurge low level.

Conclusions: We report the largest cohesive effort to control spread of vancomycin-resistant enterococci in Hong Kong. Coupled with other infection control measures, we successfully controlled vancomycinresistant enterococci to the pre-outbreak level. We have demonstrated that the monumental tasks can be achieved with meticulous planning, and thorough communication and understanding between all stakeholders.

\footnotetext{
Hong Kong Med J 2017;23:140-9

DOI: 10.12809/hkmj164939

1,2 CKC Lai ${ }^{*}, \mathrm{MB}, \mathrm{ChB}, \mathrm{FHKCPath}$

1,2 SYN Wong, MB, BS, FHKCPath

${ }^{2}$ SSY Lee, BSc (Nursing), MSC (Nursing)

${ }^{3} \mathrm{HK}$ Siu, BSc (Statistics), MPhil (Social Medicine)

${ }^{4}$ CY Chiu, BSc (Biomedical Sciences), MSc (Medical Laboratory Sciences)

1,2,3 DNC Tsang, MB, BS, FHKCPath

${ }^{4}$ MPY Ip, FRCP, FRCPath

${ }^{5}$ CT Hung, FANZCA, FHKAM (Anaesthesiology)

Department of Pathology, Queen Elizabeth Hospital, Hong Kong

Infection Control Team, Queen Elizabeth Hospital, Hong Kong

Chief Infection Control Officer's Office, Hospital Authority, Hong Kong

${ }^{4}$ Department of Microbiology, The Chinese University of Hong Kong, Hong Kong

${ }^{5}$ Queen Elizabeth Hospital, Hong Kong
} electrophoresis showed a predominant outbreak *Corresponding author: laikcc@ha.org.hk

New knowledge added by this study

- This is the largest vancomycin-resistant enterococci control study ever conducted in Hong Kong.

- We have demonstrated the infection control measures required in controlling a large outbreak in a Hong Kong public hospital setting.

- The key infection control measures are active case finding followed by case-cohorting, directly observed hand hygiene, and equipment and environmental hygiene.

Implications for clinical practice or policy

- Control of large infectious disease outbreaks and effective implementation of infection control measures can be achieved with meticulous planning, thorough communication, and understanding between all stakeholders.

\section{Introduction}

Vancomycin-resistant enterococci (VRE) is an important cause of health care-associated infection and is known to prolong hospital stay, increase treatment cost, and patient morbidityand mortality..$^{1-5}$ A VRE carrier was defined as any patient with VRE isolated from a clinical or surveillance specimen. The first case of VRE in Hong Kong was identified at 
Queen Elizabeth Hospital (QEH) in 1997. ${ }^{6}$ In 2010, VRE constituted $0.4 \%$ of all Enterococcus isolates. Apart from individual small-scale outbreaks, ${ }^{7,8}$ VRE had not gained a foothold in Hong Kong. Queen Elizabeth Hospital is the largest public acute general tertiary hospital under the administration of the Hospital Authority (HA) with 1800 beds. There are more than 160000 admissions with 104000 inpatients treated annually. A major VRE outbreak occurred in QEH in 2013. There was an abnormal increase in the incidence of VRE carriage in multiple clinical departments compared with baseline. Prior to this outbreak, VRE control measures were stipulated by the HA Guideline on Control of VRE. Active screening was not mandatory but was usually performed in contact investigations after VRE was recovered from clinical specimens. The baseline incidence of VRE never exceeded five per week prior to December 2012. Nonetheless, the incidence crept up and by March 2013, a total of 34 VRE carriers were identified in week 13 alone. This study aimed to describe in detail the approach to rapidly control VRE in our hospital.

\section{Methods}

\section{Multipronged infection control measures for vancomycin-resistant enterococci}

The hospital's control measures can be divided into two phases based on the intensity of measures with the triggering event of the constitution of QEH VRE Task Group.

\section{Emerging phase (1 January 2012 to 13 May 2013)}

(1) Find and confine-active case finding by admission screening in high prevalence wards with additional weekly screening for outbreak wards. Carriers of VRE were cohorted in either a single room or designated cubicles with a mobile curtain as segregation. Signage for contact precautions was posted at the entrance to the cohort area and at the patients' bedside. Gloves and gowns were worn when in contact with the patient or patient environment. All VRE cases and their contacts were tagged in the corporate electronic Clinical Management System.

(2) Hand hygiene-chlorhexidine-alcohol hand rub was used in clinical areas with high VRE prevalence. Only two visitors were allowed per VRE patient with their hand hygiene compliance monitored.

(3) Nursing care-all patients in Intensive Care Unit were bathed with chlorhexidine daily. Wards were advised that excreta and tube feeding should be handled by separate teams.

(4) Equipment and environment-we introduced colour-coding to all clinical wards. Two-inone disinfectants and disposable wipes were

\section{香港一所分區醫院使用全院大型篩查方案成功 控制抗萬古霉素腸道鏈球菌 \\ 賴貫之、黃溢妮、李雪怡、邵漢基、招翠儀、曾艾壯、 葉碧瑤、熊志添}

引言：抗萬古徽素耐藥性腸道鏈球菌（VRE）除了個別小規模爆發 外, 在香港並不常見。然而2013年卻在一所三級醫院內發生VRE大規 模爆發。本文描述成功控制VRE爆發所實施的感染控制措施及分享經 驗。

方法：2013年伊利沙伯醫院多個臨床部門的VRE發生率與基線相比有 異常增加。院方採取多方面感染控制措施, 其中包括一個長達 10 週的 全院直腸拭子篩查方案, 為要識別所有隱性VRE的住院帶菌病人, 以 便立即在指定的隔離病房隔離。其他關鍵的感染控制措施包括直接觀 察手部衛生及加強環境衛生。在整個抗疫過程, 院方都以透明和公開 的態度向院內及外界披露抗疫的情況。

結果：過程中順利實施所有感染控制措施。VRE直腸拭子篩查於2013 年9月 30 日至 11 月 10 日期間進行。我們搜集來自 11 個部門46個病房共 7053個直腸拭子樣本。整體VRE帶菌率為2.8\%（201/7053）。脈衝 場凝膠電測試顯示有疫情爆發。我們成功中止了這次VRE爆發並把帶 第率控制至爆發前的水平。

結論：這是香港迄今最大規模的VRE感染控制工作。聯同其他感染控 制措施, 我們成功控制VRE疫情並把VRE達至爆發前的水平。與各 持份者的緊密溝通及進行大型篩查前的精心策劃, 乃是今次成功控制 VRE爆發的關鍵

provided to clinical wards to improve two-step cleaning. Dedicated non-critical patient care equipment was provided for all VRE cases. Hydrogen peroxide vaporisation sessions were used to disinfect non-critical patient care equipment. Cleaners were coached by infection control nurses and their performance was gauged by environmental sampling and fluorescence markers.

(5) Open disclosure-all outbreaks were disclosed through press release.

\section{Intensive control phase (13 May 2013 to 10} November 2013)

(1) Command and control-a VRE Task Group was formed with clear administrative mandates from the Hospital Chief Executive, head of nursing, and head of administrative services. The Task Group included senior representatives from clinical departments, human resources, laboratories, and infection control teams. Weekly meetings were held. Local experts from HA Head Office, Centre for Health Protection, and a local university were also invited to jointly devise an intensive VRE control programme.

(2) Active screening-the pan-hospital VRE screening was the hallmark of this period; it exemplified the determination of the hospital administration. Rectal swabs were collected to identify VRE carriers in different stages. Each 
ward performed a point prevalence screening followed by 2 weeks of admission and discharge screening. The screening of 46 hospital wards from 11 departments was to be completed within 10 weeks.

Carriage of VRE is associated with additional length of stay. ${ }^{1}$ A sudden surge in VRE cases would result in blockage of admissions, resulting in redirection of emergency admissions to other hospitals. Based on prevalence figures from contact investigations in previous localised VRE outbreaks (range, 0\%-20\%), bed status and occupancy rates, 126 VRE cases would be identified on the first day of screening alone, 566 cases would be identified at the end of the screening, assuming $10 \%$ of our inpatients were VRE carriers. To avoid overwhelming the hospital services due to inadequate isolation facilities, a modified risk-based pan-hospital screening was adopted with consideration of the following parameters: daily number of specimens, daily number of VRE carriers identified, consequent additional length of stay, and designated cohort ward capacity. The final schedule had exacted the number of specimens to be taken by ward and date over a 10-week period and was agreed by all stakeholders.

To segregate VRE carriers, a VRE ward was created to avert cross-transmission. Bed capacity was 'created' by rescheduling elective procedures from both medical and surgical teams.

To avoid inadvertently overloading the hospital's capacity during active screening, two 'brake points' were set, namely number of patients waiting at the emergency department at 7 am each morning for emergency hospital admission should not exceed 30, and total VRE cases identified should not exceed 25 per day. When these points were met, screening on that particular day would stop. A real-time close monitoring communication group using instant messaging (WhatsApp) was formed to connect all key stakeholders on a 24/7 basis.

Other additional measures included:

- Hand hygiene-audit results of hand hygiene compliance were reported to department and hospital administration on a weekly basis. Alcoholic hand rub dispensers were installed in patient toilets. Hand hygiene before meals and medications in all conscious hospitalised patients were directly observed.

- Nursing care-disposable disinfection wipes were provided to optimise disinfection of commodes, bedpans, and urinals. On-site coaching was provided by infection control nurses about contamination-prone procedures, particularly napkin change and care for nasogastric tube.

- Equipment and environment-we increased cleaning staff manpower by recruiting additional external cleaning staff and instigating an overtime allowance for existing staff. The frequency of changing privacy curtains was shortened from monthly to biweekly for all VRE carriers. Cleaning efficacy was monitored by regular environmental sampling using Polywipe (Medical Wire \& Equipment/Wiltshire, United Kingdom) in wards where the outbreak was detected.

- Staff engagement, education, and communication-staff forums were organised so all parties would understand the importance of VRE and their role as health care workers, with dedicated sessions in Cantonese for supporting staff.

- Open disclosure-the result from the panhospital screening was released to hospital administration and HA head office on a daily basis.

\section{Laboratory protocol}

Rectal swabs and stool specimens were inoculated onto chromID VRE agar (bioMérieux, France) and incubated at $35^{\circ} \mathrm{C} \pm 2^{\circ} \mathrm{C}$ according to the manufacturer's recommendations. The agar plates were examined daily for 2 days. Suspected colonies were identified to be Enterococcus species by both MALDI-TOF (Vitek-MS, bioMérieux) and conventional microbiological methods of Gram stain and biochemical reactions. Vancomycin resistance was confirmed by E-test (bioMérieux, France) according to Clinical Laboratory Standards Institute breakpoints. ${ }^{9}$ Detection of vancomycin resistance genes was performed by the local reference laboratory. Strains were typed by pulsedfield gel electrophoresis (PFGE) and patterns of SmaI-restricted chromosomal DNA analysed by unweighted pair group method with arithmetic mean (UPGMA) using the BioNumerics software (Applied Maths). ${ }^{10}$

\section{Hand hygiene compliance audit}

We adopted the World Health Organization (WHO) hand hygiene observation tools by directly observing compliance with the WHO five moments. The observation was conducted by infection control nurses using a WHO standardised audit form. Nurses, supporting staff, doctors, and allied health personnel were included for observation.

\section{Antibiotics consumption data}

The consumption of vancomycin, ceftazidime, and ceftriaxone in QEH between week 1 of 2012 and week 39 of 2015 was retrieved from the Clinical Data Analysis and Reporting System. Consumption data were presented in defined daily dose.

\section{Statistical analysis}

The relationship between VRE carriage, a binary 
dependent variable, and five independent variables related to patients' demographic background and hospitalisation history were analysed by univariate methods (Chi squared test supplemented with measurement of the association [odds ratio for binary variables and Spearman's correlation for ordinal variables]) and the significant independent variables were included in the subsequent multiple logistic regression model. The 30-day mortality between groups was analysed by Chi squared test.

In multiple logistic regression, one category of each independent variable was selected as 'reference category' to compare with other categories in the variable and the odds ratio calculated. Likelihood ratio test was used to compare the final model with null model and Hosmer-Lemeshow test was used to evaluate the goodness-of-fit of the final model. The Statistical Package for the Social Sciences (SPSS Windows version 21.0; IBM Corp, Armonk [NY], United States) was used for data analysis.

\section{Results}

Our multipronged infection control measures successfully brought down VRE to pre-outbreak level. Prior to screening, 150 non-emergency procedures were rescheduled. The screening was conducted between 30 September and 10 November 2013. A total of 7053 specimens from 4966 patients were collected-1422 from point prevalence, 4225 from admission, and 1406 on discharge (Table 1). We managed to complete the screening schedule without meeting the brake points.

The baseline incidence of VRE never exceeded five per week prior to the current outbreak. After December 2012, it crept up and peaked at week 13 of 2013 with 34 new VRE cases identified. After the pan-hospital screening, the incidence dropped to no more than five cases per week after March 2015 (Fig 1).

Of all the specimens screened, 2.8\% (201/7053) were positive for VRE-65.7\% (132/201) of VRE came from the specialty of medicine, $19.9 \%$ (40/201) from the surgical stream (all surgical subspecialties except neurosurgery and orthopaedics). The point prevalence of VRE was $5.8 \%(83 / 1422)$, admission prevalence was $1.8 \%(75 / 4225)$, and discharge prevalence was $3.1 \%(43 / 1406)$. Risk factors for VRE carriage included male gender, residence in a home for the elderly, older age, longer hospital stay, and more hospitalisation episodes in the previous 90 days prior to screening (Table 2). From logistic regression results compared with the reference group, there was a progressive increase in the risk of VRE carriage with increasing age, and increase in days of hospitalisation in the previous 90 days prior to screening, but not with increasing episodes of hospitalisation in the previous 90 days prior to screening (Table 3).

\section{Infection control measures}

A total of 28588 hand hygiene observations were made in 2013. The compliance rate improved from

TABLE I. Results of the pan-hospital screening of VRE based on clinical departments

\begin{tabular}{|c|c|c|c|c|c|c|c|c|}
\hline \multirow{2}{*}{$\begin{array}{l}\text { Ward } \\
\text { specialty }\end{array}$} & \multicolumn{2}{|r|}{ All } & \multicolumn{2}{|c|}{ Prevalence survey } & \multicolumn{2}{|c|}{ Admission screening } & \multicolumn{2}{|c|}{ Discharge screening } \\
\hline & $\begin{array}{l}\text { Total No. } \\
\text { tested }\end{array}$ & $\begin{array}{c}\text { No. }(\%) \text { of } \\
\text { positive results }\end{array}$ & $\begin{array}{c}\text { Total No. } \\
\text { tested }\end{array}$ & $\begin{array}{c}\text { No. }(\%) \text { of } \\
\text { positive results }\end{array}$ & $\begin{array}{c}\text { Total No. } \\
\text { tested }\end{array}$ & $\begin{array}{c}\text { No. }(\%) \text { of } \\
\text { positive results }\end{array}$ & $\begin{array}{l}\text { Total No. } \\
\text { tested }\end{array}$ & $\begin{array}{c}\text { No. }(\%) \text { of } \\
\text { positive results }\end{array}$ \\
\hline MED & 2892 & $132(4.6)$ & 694 & $58(8.4)$ & 1457 & $47(3.2)$ & 741 & $27(3.6)$ \\
\hline SUR & 2449 & $37(1.5)$ & 211 & $7(3.3)$ & 1793 & $18(1.0)$ & 445 & $12(2.7)$ \\
\hline O\&T & 884 & $24(2.7)$ & 148 & 13 (8.8) & 607 & 7 (1.2) & 129 & $4(3.1)$ \\
\hline NS & 294 & $2(0.7)$ & 74 & $2(2.7)$ & 157 & 0 & 63 & 0 \\
\hline ONC & 128 & 0 & 65 & 0 & 54 & 0 & 9 & 0 \\
\hline Eye \& ENT & 102 & $1(1.0)$ & 17 & 0 & 71 & $1(1.4)$ & 14 & 0 \\
\hline ICU & 80 & $3(3.8)$ & 39 & $3(7.7)$ & 41 & 0 & 0 & $0(\mathrm{~N} / \mathrm{A})$ \\
\hline PAE & 77 & 0 & 77 & 0 & 0 & $0(\mathrm{~N} / \mathrm{A})$ & 0 & $0(\mathrm{~N} / \mathrm{A})$ \\
\hline O\&G & 68 & 0 & 64 & 0 & 4 & 0 & 0 & $0(\mathrm{~N} / \mathrm{A})$ \\
\hline CTS & 60 & 2 (3.3) & 31 & 0 & 27 & $2(7.4)$ & 2 & 0 \\
\hline Custodial & 9 & 0 & 0 & $0(\mathrm{~N} / \mathrm{A})$ & 8 & 0 & 1 & 0 \\
\hline Renal & 6 & 0 & 2 & 0 & 3 & 0 & 1 & 0 \\
\hline Private & 4 & 0 & 0 & $0(N / A)$ & 3 & 0 & 1 & 0 \\
\hline Total & 7053 & $201(2.8)$ & 1422 & $83(5.8)$ & 4225 & 75 (1.8) & 1406 & $43(3.1 \%)$ \\
\hline
\end{tabular}

Abbreviations: CTS = cardiothoracic surgery; ENT = ear, nose, and throat; ICU = intensive care unit; MED = medicine; N/A = not applicable; NS = neurosurgery; O\&G = obstetrics and gynaecology; O\&T = orthopaedics and traumatology; ONC = oncology; PAE = paediatrics; SUR = surgery; VRE = vancomycin-resistant enterococci 


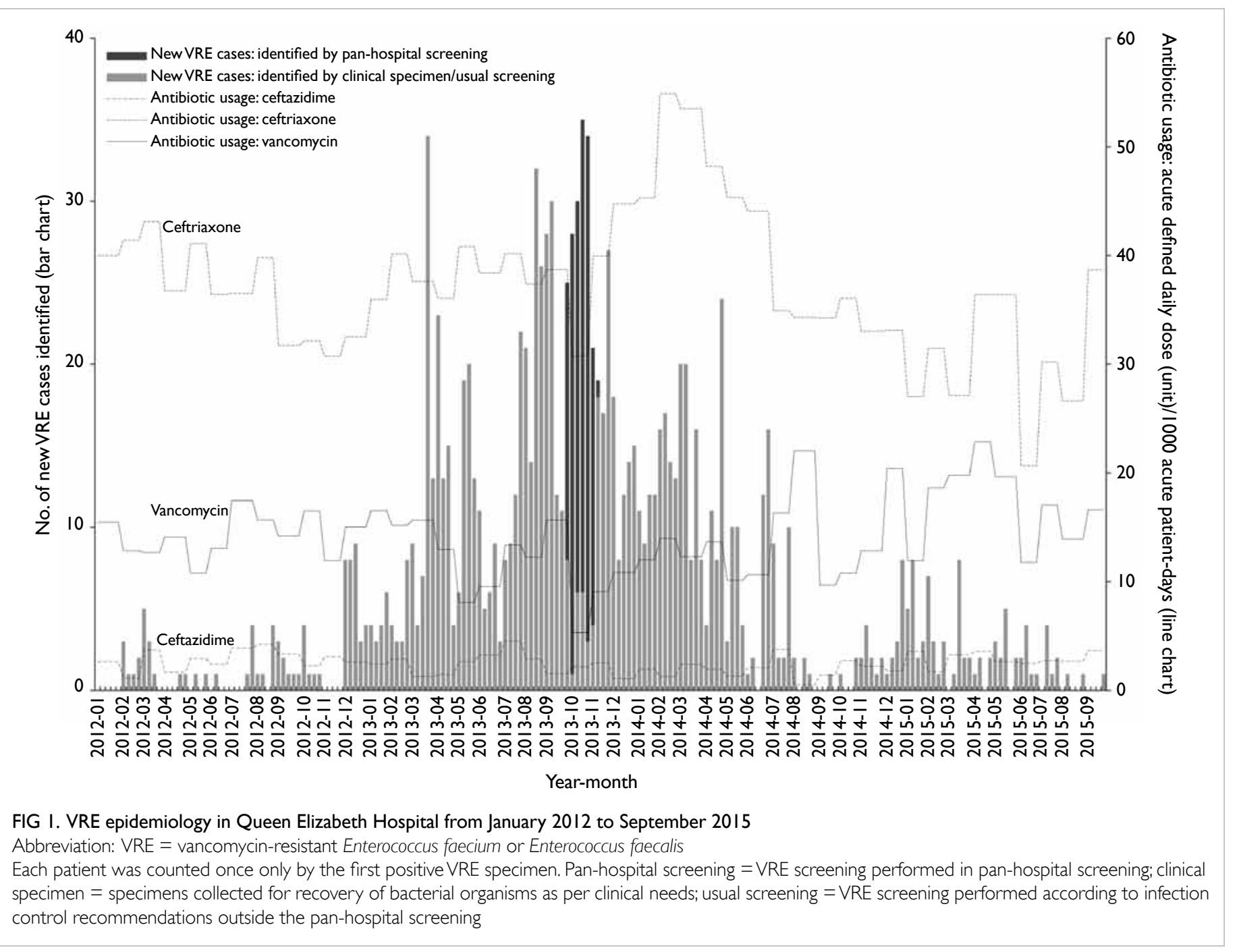

$37 \%$ in the first quarter of 2013 to $73 \%$ in the fourth quarter of 2013. The improvement was seen across all departments and all staff groups. A total of 30 sessions of on-site education about napkin change, nasogastric tube care, and environmental cleaning were provided with 88 napkin care procedures observed in 28 wards. Furthermore, 37 hydrogen peroxide vapour sessions were offered to disinfect non-critical equipment; and 15 staff forums dedicated to VRE control were held with a total of 1339 attendances.

\section{Microbiology}

During the screening period, 105 VRE isolates recovered from the pan-hospital screening were all vanA gene carrying Enterococcus faecalis. They were analysed with eight unrelated archived VRE strains. The PFGE patterns of SmaI-restricted chromosomal DNA of 113 VRE isolates are shown in Figure 2. Dendrogram of PFGE patterns was obtained by UPGMA method. A predominant cluster A was classified using a cut-off at $90 \%$ similarity, as calculated by Dice coefficient with $1 \%$ position tolerance and $2 \%$ band optimisation. Cluster A comprised 49 strains from the current pan-hospital screening and one unrelated archived strain from another hospital.

\section{Carriage of vancomycin-resistant enterococci and 30-day mortality}

During the pan-hospital screening period, the 30-day all-cause mortality of all VRE carriers identified in the pan-hospital screening and non-VRE carriers were $20.5 \%$ and $6.1 \%$, respectively. The odds ratio was 3.93 (95\% confidence interval, 2.68-5.78). When compared with previously known VRE carriers but with negative VRE screening results in the same period (13.6\%), the 30-day all-cause mortality were $20.5 \%$ and $13.6 \%$, respectively. The odds ratio was 1.64 (95\% confidence interval, 0.71-3.76).

\section{Antibiotic consumption}

There was no significant change in consumption of vancomycin or ceftazidime during the emerging 
TABLE 2. Demographic data for VRE-positive patients

\begin{tabular}{|c|c|c|c|c|}
\hline \multirow[t]{2}{*}{ Variable } & \multicolumn{2}{|c|}{ No. (\%) of patients } & \multirow[t]{2}{*}{$P$ value } & \multirow{2}{*}{$\begin{array}{l}\text { Measurement of the } \\
\text { association*, odds } \\
\text { ratio }(95 \% \mathrm{Cl}) \dagger\end{array}$} \\
\hline & VRE carrier & Non-VRE carrier & & \\
\hline Sex & & & 0.001 & $1.60(1.22-2.11)$ \\
\hline Female & $85(3.6)$ & 2253 (96.4) & & \\
\hline Male & $150(5.7)$ & 2478 (94.3) & & \\
\hline Admission from OAH & & & $<0.001$ & $3.21(2.42-4.27)$ \\
\hline No & $157(3.7)$ & 4096 (96.3) & & \\
\hline Yes & $78(11.0)$ & $634(89.0)$ & & \\
\hline Admission age (years) $\ddagger$ & & & $<0.001$ & 0.102 \\
\hline$\leq 29$ & $3(0.6)$ & $461(99.4)$ & & \\
\hline $30-49$ & $16(2.3)$ & $668(97.7)$ & & \\
\hline $50-69$ & $53(3.7)$ & $1371(96.3)$ & & \\
\hline$\geq 70$ & $163(6.8)$ & 2230 (93.2) & & \\
\hline Hospital stay (days) in HA hospitals in the previous 90 days (grouped) & & & $<0.001$ & 0.320 \\
\hline 0 & $53(1.4)$ & $3824(98.6)$ & & \\
\hline $1-20$ & $44(9.2)$ & $435(90.8)$ & & \\
\hline $21-40$ & $58(17.3)$ & $278(82.7)$ & & \\
\hline $41-60$ & $38(26.4)$ & $106(73.6)$ & & \\
\hline$\geq 61$ & $42(32.3)$ & $88(67.7)$ & & \\
\hline Hospitalisation episodes in the previous 90 days (grouped) & & & $<0.001$ & 0.206 \\
\hline 0 & $11(0.5)$ & $2182(99.5)$ & & \\
\hline $1-2$ & $146(6.5)$ & $2116(93.5)$ & & \\
\hline $3-4$ & $57(14.4)$ & $340(85.6)$ & & \\
\hline$\geq 5$ & $21(18.4)$ & $93(81.6)$ & & \\
\hline Total & $235(4.7)$ & 4731 (95.3) & & \\
\hline
\end{tabular}

Abbreviations: $\mathrm{Cl}$ = confidence interval; $\mathrm{HA}$ = Hospital Authority; $\mathrm{OAH}=$ old-age home; $\mathrm{VRE}=$ vancomycin-resistant enterococci

* Outcome: patient ever has VRE-positive result = yes

† Odds ratio is used for binary independent variables ('Sex' and 'Admission from OAH') while Spearmen's correlation is used for ordinal independent variables

$\mp$ Missing data of I case in the OAH admissions and admission age

phase or during and beyond the intensive rebuffed the screening programme as they sensed control phase. There was an apparent increase in extra work and doubted its effectiveness. Overseas consumption of ceftriaxone noted after the intensive experience has shown that once VRE becomes phase in the first half of 2014 (Fig 1).

\section{Discussion}

Identification of VRE carriers, segregation of primary sources, hand hygiene, and environmental hygiene are the critical success factors in controlling the VRE outbreak. The territory-wide effort to control the emergence of VRE in public hospitals in Hong Kong has been discussed elsewhere. ${ }^{11}$ Our study revealed the critical elements involved in controlling a multisourced VRE outbreak in a major tertiary hospital. We believe our failure to contain VRE in the emerging phase was in part due to the lack of perceived need of staff for VRE control as well as skepticism about the effectiveness of infection control measures. Senior clinicians may be ambivalent towards our approach due to perceived loss of autonomy. Frontline staff hospital endemic, eradication is difficult despite the best efforts. ${ }^{12-14}$

We faced an additional challenge of an absence of facilities to completely segregate VRE carriers. Our hospital faces overcrowding on a daily basis with bed occupancy often exceeding $100 \%$, and reaching as high as $130 \%$ during influenza seasons. Studies have shown that bed occupancy, isolation room availability, and staffing have a direct impact on ease of VRE control.15,16 Our difficulties were compounded by lack of inter-bed spacing and limited toilet facilities as the hospital was designed more than 60 years ago, and the need to keep the hospital functioning at all times.

In the intensive control phase, commitment from hospital administration became visible as a result of the pan-hospital screening. Close liaison between departments, careful and extensive planning 
TABLE 3. Logistic regression results (outcome: patient ever has VRE-positive result $=$ yes)

\begin{tabular}{|c|c|c|}
\hline Variable & $P$ value & Odds ratio $(95 \% \mathrm{Cl})^{\star} \dagger$ \\
\hline Sex & 0.001 & \\
\hline Female & & Reference category \\
\hline Male & & $1.67(1.24-2.25)$ \\
\hline Admission from $\mathrm{OAH}$ & 0.002 & \\
\hline No & & Reference category \\
\hline Yes & & $1.70(1.22-2.36)$ \\
\hline Admission age (years) & $<0.001$ & \\
\hline$\leq 29$ & & Reference category \\
\hline $30-49$ & & $5.05(1.41-18.06)$ \\
\hline $50-69$ & & $6.06(1.82-20.17)$ \\
\hline$\geq 70$ & & $9.84(3.00-32.29)$ \\
\hline Hospital stay (days) in HA hospitals in the previous 90 days (grouped) & $<0.001$ & \\
\hline 0 & & Reference category \\
\hline $1-20$ & & $4.17(2.67-6.53)$ \\
\hline $21-40$ & & $9.20(5.83-14.53)$ \\
\hline $41-60$ & & $16.17(9.54-27.39)$ \\
\hline$\geq 61$ & & $26.22(15.56-44.18)$ \\
\hline Hospitalisation episodes in the previous 90 days (grouped) & $<0.001$ & \\
\hline 0 & & Reference category \\
\hline $1-2$ & & $4.65(2.38-9.07)$ \\
\hline $3-4$ & & $2.87(1.33-6.19)$ \\
\hline$\geq 5$ & & $2.73(1.13-6.56)$ \\
\hline Constant & 0.036 & \\
\hline \multicolumn{3}{|c|}{$\begin{array}{l}\text { Abbreviations: } \mathrm{Cl}=\text { confidence interval; } \mathrm{HA}=\text { Hospital Authority; } \mathrm{OAH}=\text { old-age home; } \mathrm{VRE}=\text { vancomycin-resistant entero } \\
\text { * Versus reference category } \\
+ \text { Comparison with null model using likelihood ratio test: } \mathrm{P}<0.05 \text { (significantly better than null model); Hosmer-Lemeshow } \\
\text { goodness-of-fit test: } \mathrm{P}>0.05 \text { (the final model fits well) }\end{array}$} \\
\hline
\end{tabular}

with input from the frontline at every step, effective communication, and staff engagement were also key to our success. Some researchers have questioned the effectiveness of active surveillance cultures in reducing VRE transmission. ${ }^{17}$ Others have suggested that VRE will not be successfully controlled if the policy excludes asymptomatic VRE colonisation. ${ }^{18-21}$ We believed it was necessary to take drastic action and perform active screening of the whole hospital.

Our planning took reference from similar overseas experiences. Christiansen et $\mathrm{al}^{18}$ successfully controlled VRE by screening 19658 patients and found 169 patients from 23 wards to be colonised with vanB-containing Enterococcus faecium in 6 months. Their experience was different from ours as they had fewer cases. Moretti et al ${ }^{19}$ reported their extensive active surveillance with enhanced infection control measures in a Brazilian teaching hospital. They performed 8692 rectal swabs for VRE (mean, 300 swabs/month), with an overall positive rate of $3.7 \%$. In their 2.5 -year intervention, their VRE positive rate decreased from $7.2 \%$ in 2007 to $1.5 \%$ in 2009 . Kurup et $\mathrm{al}^{20}$ reported their experience in a large Singaporean hospital. They performed a large-scale screening of 4924 patients over 2 months and successfully reduced the positive rate from $11.4 \%$ at the peak of the outbreak to $4.2 \%$ at the end of screening. We did not observe a decline over the pan-hospital screening period as in the Singaporean experience. It was because we deliberately spaced out the departments with a high VRE prevalence throughout the 10 -week period to avoid overwhelming the hospital's facilities.

Rapid laboratory turnaround time is another key element. ${ }^{22}$ It was soon evident that the hospital laboratory could not handle the additional specimens alone. Assistance from three HA microbiology laboratories was sought. A huge amount of liaison work with extensive communication between laboratory directors, senior medical technologists, and scientific officers followed to ensure the smooth running of this unprecedented inter-laboratory 


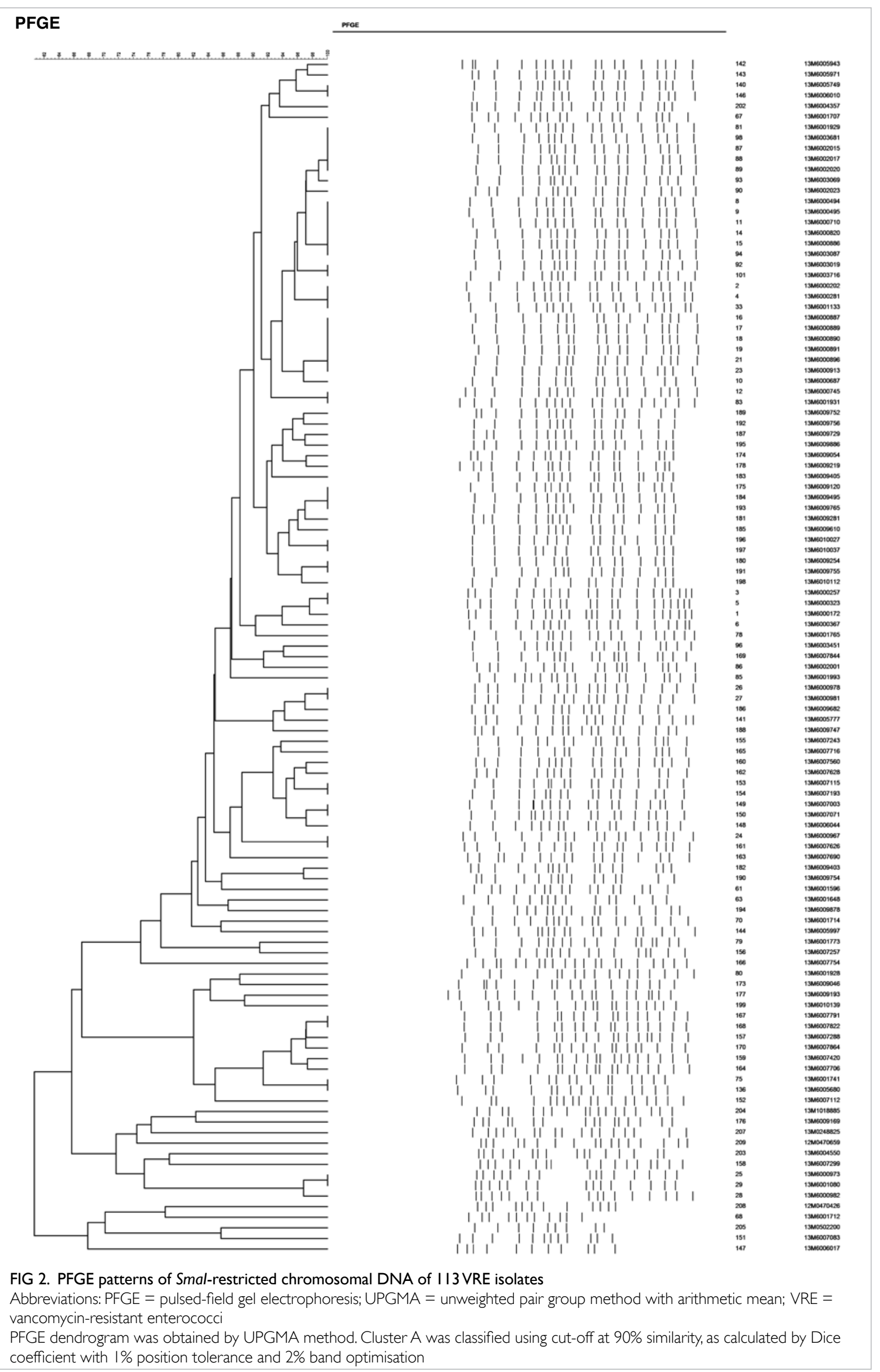


cooperation. A unified set of logistics was established, governing the tiniest details. Procurement of key reagents like chromogenic agar was coordinated centrally with support from the HA head office.

Hygiene management has been shown to be important in controlling VRE in endemic areas. ${ }^{16,23,24}$ Contamination of the hospital environment by VRE, and occurrence of cross-contamination, either through the hands of health care workers, equipment, or surfaces is well known. ${ }^{25-27}$ The association of environmental contamination and the occurrence of an outbreak has also been well established. ${ }^{18,28-30}$

The improvement in hand hygiene compliance from approximately $37 \%$ to $73 \%$ was remarkable. Several explanations are postulated: (1) the VRE Task Group escalated the need for urgent improvement. The weekly reporting of hand hygiene compliance rate via the VRE workgroup created a driving force at an administrative level; (2) we implemented directly observed hand hygiene before meals and when taking medications in all conscious hospitalised patients; (3) we actively engaged infection control link nurses, creating a collective learning opportunity that has facilitated collaboration and system thinking; and (4) making the hand hygiene compliance data visible (and comparing with other wards/departments) might change the behaviour of many. ${ }^{31}$

All the VRE recovered in the pan-hospital screening was vanA-containing Enterococcus faecium. The PFGE patterns showed 49 out of the 105 pan-hospital screening isolates belonged to a single cluster (cluster A), signifying the possibility of clonal spread of a dominant strain, with co-circulation of various less dominant strains. Some clones may have developed de novo. Further analysis of these strains will allow a more thorough understanding of the transmission dynamics within the hospital, and whether the outbreak clone has a survival advantage over other clones.

We identified residents of homes for the elderly, advanced age, and prolonged hospitalisation as risk factors for VRE carriage. This is most likely due to their associated co-morbidities rather than the individual factors per se. It is unknown why men were at a higher risk than women. It might have been a chance finding since more outbreaks occurred in male wards before and during the study period than female wards.

Antibiotics, especially vancomycin and third-generation cephalosporins like ceftazidime and ceftriaxone, were known to be a risk for VRE colonisation. We did not observe significant changes in the consumption of vancomycin or ceftazidime throughout the study period. Nonetheless, an increase in consumption of ceftriaxone was observed in the first half of 2014. We hypothesise the increase might be a squeeze-the-balloon effect by actively avoiding big gun antibiotics, or an artefact due to irregularities in returning ward antibiotic stock to the hospital pharmacy.

We observed a significant increase in 30-day mortality in VRE carriers identified in the panhospital screening when compared with those who tested negative for VRE during the same period. However, when we compared the VRE carriers identified in pan-hospital screening with those who tested VRE negative but were known to have had previous VRE carriage, they were not significantly different. Confounding factors like length of hospitalisation and co-morbidities are likely causes of this observation. Further analysis of these factors is required to give a more definitive answer.

The pan-hospital screening was immediately followed by the 10-week HA-wide targeted surveillance screening. Any patient with a history of admission to any one of the hospitals in Hong Kong within 3 months, or on haemodialysis, were actively screened for VRE on admission. The VRE level continues to be maintained at a low level, 3 years after the intensive period that ended in 2013. This is important because a one-time effort is often difficult and does not always result in a lasting effect unless a system and culture change has been brought about.

A limitation of this study was that the analysis was performed retrospectively. We retrospectively studied the odds ratio after both the exposure and the outcomes had already occurred. It is in contrast to prospective cohort studies where participants are enrolled and then followed over time to identify the occurrence of VRE carriage. In addition, sustained control of VRE is multifactorial and not dependent on any one isolated intervention. Although there were no large-scale outbreaks or VRE control programmes in other hospitals, interdependence among hospitals and other health care facilities are well described.

\section{Conclusions}

We have successfully controlled a multiple-sourced hospital-wide VRE outbreak in a tertiary hospital with multipronged infection control measures. The need to establish a close working relation between all stakeholders in the hospital cannot be overemphasised. Our experience is useful to other hospitals challenged by VRE or other multidrugresistant bacteria.

\section{Acknowledgements}

We are grateful to all the medical, nursing, and supporting staff in Queen Elizabeth Hospital who assisted in VRE control. We thank the microbiology laboratories of Princess Margaret Hospital, United Christian Hospital, and Queen Mary Hospital for their excellent support in handling VRE specimens during pan-hospital screening. 


\section{Declaration}

We would like to acknowledge the Food and Health Bureau, Hong Kong SAR for supporting the typing of the VRE strains under Health and Medical Research Fund (Commissioned HMRF Project No. CU-15-B5).

\section{References}

1. Cheah AL, Spelman T, Liew D, et al. Enterococcal bacteraemia: factors influencing mortality, length of stay and costs of hospitalization. Clin Microbiol Infect 2013;19:E181-9.

2. Vergis EN, Hayden MK, Chow JW, et al. Determinants of vancomycin resistance and mortality rates in enterococcal bacteremia: A prospective multicenter study. Ann Intern Med 2001;135:484-92.

3. Lloyd-Smith P, Younger J, Lloyd-Smith E, Green H, Leung V, Romney MG. Economic analysis of vancomycin-resistant enterococci at a Canadian hospital: assessing attributable cost and length of stay. J Hosp Infect 2013;85:54-9.

4. Carmeli Y, Eliopoulos G, Mozaffari E, Samore M. Health and economic outcomes of vancomycin-resistant enterococci. Arch Intern Med 2002;162:2223-8.

5. Muto CA, Giannetta ET, Durbin LJ, Simonton BM, Farr BM. Cost-effectiveness of perirectal surveillance cultures for controlling vancomycin-resistant Enterococcus. Infect Control Hosp Epidemiol 2002;23:429-35.

6. Chuang VW, Tsang DN, Lam JK, Lam RK, Ng WH. An active surveillance study of vancomycin-resistant Enterococcus in Queen Elizabeth Hospital, Hong Kong. Hong Kong Med J 2005;11:463-71.

7. Cheng VC, Tai JW, Ng ML, et al. Extensive contact tracing and screening to control the spread of vancomycinresistant Enterococcus faecium ST414 in Hong Kong. Chin Med J 2012;125:3450-7.

8. Cheng VC, Chan JF, Tai JW, et al. Successful control of vancomycin-resistant Enterococcus faecium outbreak in a neurosurgical unit at non-endemic region. Emerg Health Threats J 2009;2:e9.

9. Clinical and Laboratory Standards Institute (CLSI). Performance standards for antimicrobial susceptibility testing: twenty-third informational supplement M100-S23. Wayne, PA: CLSI; 2013.

10. Miranda AG, Singh KV, Murray BE. DNA fingerprinting of Enterococcus faecium by pulsed-field gel electrophoresis may be a useful epidemiologic tool. J Clin Microbiol 1991;29:2752-7.

11. Cheng VC, Tai JW, Chau PH, et al. Successful control of emerging vancomycin-resistant enterococci by territorywide implementation of directly observed hand hygiene in patients in Hong Kong. Am J Infect Control 2016;44:116871.

12. Willems RJ, Top J, van Santen M, et al. Global spread of vancomycin-resistant Enterococcus faecium from distinct nosocomial genetic complex. Emerg Infect Dis 2005;11:821-8.

13. Arias CA, Murray BE. The rise of the Enterococcus: beyond vancomycin resistance. Nat Rev Microbiol 2012;10:26678.

14. Werner G, Coque TM, Hammerum AM, et al. Emergence and spread of vancomycin resistance among enterococci in Europe. Euro Surveill 2008;13.pii:19046.
15. Arias CA, Mendes RE, Stilwell MG, Jones RN, Murray BE. Unmet needs and prospects for oritavancin in the management of vancomycin-resistant enterococcal infections. Clin Infect Dis 2012;54 Suppl 3:S233-8.

16. Aumeran C, Baud O, Lesens O, Delmas J, Souweine B, Traoré O. Successful control of a hospital-wide vancomycin-resistant Enterococcus faecium outbreak in France. Eur J Clin Microbiol Infect Dis 2008;27:1061-4.

17. Huskins WC, Huckabee CM, O'Grady NP, et al. Intervention to reduce transmission of resistant bacteria in intensive care. N Engl J Med 2011;364:1407-18.

18. Christiansen KJ, Tibbett PA, Beresford W, et al. Eradication of a large outbreak of a single strain of $\operatorname{van} B$ vancomycinresistant Enterococcus faecium at a major Australian teaching hospital. Infect Control Hosp Epidemiol 2004;25:384-90.

19. Moretti ML, de Oliveira Cardoso LG, Levy CE, et al. Controlling a vancomycin-resistant enterococci outbreak in a Brazilian teaching hospital. Eur J Clin Microbiol Infect Dis 2011;30:369-74.

20. Kurup A, Chlebicki MP, Ling ML, et al. Control of a hospital-wide vancomycin-resistant Enterococci outbreak. Am J Infect Control 2008;36:206-11.

21. Lee SC, Wu MS, Shih HJ, et al. Identification of vancomycinresistant enterococci clones and inter-hospital spread during an outbreak in Taiwan. BMC Infect Dis 2013;13:163.

22. Delmas J, Robin F, Schweitzer C, Lesens O, Bonnet R. Evaluation of a new chromogenic medium, ChromID VRE, for detection of vancomycin-resistant Enterococci in stool samples and rectal swabs. J Clin Microbiol 2007;45:2731-3.

23. Nolan SM, Gerber JS, Zaoutis T, et al. Outbreak of vancomycin-resistant enterococcus colonization among pediatric oncology patients. Infect Control Hosp Epidemiol 2009;30:338-45.

24. Morris-Downes M, Smyth EG, Moore J, et al. Surveillance and endemic vancomycin-resistant enterococci: some success in control is possible. J Hosp Infect 2010;75:228-33.

25. Ramsey AM, Zilberberg MD. Secular trends of hospitalization with vancomycin-resistant enterococcus infection in the United States, 2000-2006. Infect Control Hosp Epidemiol 2009;30:184-6.

26. Muto CA, Jernigan JA, Ostrowsky BE, et al. SHEA guideline for preventing nosocomial transmission of multidrugresistant strains of Staphylococcus aureus and enterococcus. Infect Control Hosp Epidemiol 2003;24:362-86.

27. Morris JG Jr, Shay DK, Hebden JN, et al. Enterococci resistant to multiple antimicrobial agents, including vancomycin. Establishment of endemicity in a university medical center. Ann Intern Med 1995;123:250-9.

28. Rossini FA, Fagnani R, Leichsenring ML, et al. Successful prevention of the transmission of vancomycin-resistant enterococci in a Brazilian public teaching hospital. Rev Soc Bras Med Trop 2012;45:184-8.

29. Boyce JM. Environmental contamination makes an important contribution to hospital infection. J Hosp Infect 2007;65 Suppl 2:50-4.

30. Harris AD. How important is the environment in the emergence of nosocomial antimicrobial-resistant bacteria? Clin Infect Dis 2008;46:686-8.

31. Kirkland KB, Homa KA, Lasky RA, Ptak JA, Taylor EA, Splaine ME. Impact of a hospital-wide hand hygiene initiative on healthcare-associated infections: results of an interrupted time series. BMJ Qual Saf 2012;21:1019-26. 